\title{
Conifer growth and reproduction in urban forest fragments: Predictors of future responses to global change?
}

\author{
Anna M. O'Brien • Ailene K. Ettinger • \\ Janneke HilleRisLambers \\ Published online: 12 July 2012 \\ (C) The Author(s) 2012. This article is published with open access at Springerlink.com
}

\begin{abstract}
Global change has a large and growing influence on forests, particularly in urban and urbanizing areas. Compared to rural forests, urban forests may experience warmer temperatures, higher $\mathrm{CO}_{2}$ levels, and greater nitrogen deposition, with exacerbated differences at urban forest edges. Thus, comparing urban to rural forests may help predict future effects of global change on forests. We focused on the conifer western red-cedar (Thuja plicata) to test three hypotheses: at urban forest edges, relative to rural forests and urban forest centers, trees experience 1) higher temperatures and nitrogen levels, 2) lower seedling recruitment, and 3) greater growth. We additionally tested anecdotal reports that 4) tree seedling recruitment in urban and rural forests is much lower than in "pristine" old-growth forests. To test these hypotheses, we quantified air temperature, soil nitrate, adult T. plicata growth and seedling recruitment in five urban and three rural parks at both forest edges and centers. We also quantified T. plicata recruitment at five old-growth "pristine" sites. Temperatures were highest at urban forest edges, and soil nitrate was highest in urban forests. In urban relative to rural forests, we observed greater $T$. plicata growth, but no difference in seedling densities. However, seedling densities were lower in urban and rural forests than in old-growth forests. In all, our results suggest urban influences enhance adult $T$. plicata growth, but not seedling recruitment. Recruitment in urban and rural forests was reduced compared to old-growth forests, implying that fragmentation and logging reduce $T$. plicata seedling recruitment.
\end{abstract}

Keywords Urban forests $\cdot$ Global change $\cdot$ Heat island $\cdot$ Nitrogen deposition $\cdot$ Seedling recruitment . Tree growth

\section{Introduction}

Cities can be used to study global change effects on forests because urban forest fragments are exposed to conditions that rural forests may experience in the future. For example, in cities, nitrogen deposition onto soils is greater due to sources such as fertilizers and car

\footnotetext{
A. M. O’Brien $(\bowtie)$

Department of Ecology \& Evolution, University of California, One Shields Avenue, Davis, CA 95616-5270, USA

e-mail: amobrien@ucdavis.edu
}

A. K. Ettinger $\cdot$ J. HilleRisLambers

Department of Biology, University of Washington, Seattle, WA 98195-1800, USA 
exhaust (Lovett et al. 2000), $\mathrm{CO}_{2}$ levels are elevated (Pataki et al. 2003; Ziska et al. 2004), urban heat island effects cause warmer temperatures (Taha 1997), and exotic species propagules are at higher densities (Lonsdale 1999). Together, these variables can be thought of as an "urban influence", and they represent the future conditions all forests may experience as humans continue to modify the environment (Carreiro and Tripler 2005). Therefore, urban parks can be utilized as "natural" global change experiments, useful for predicting the response of forests to combined influences of global change factors.

Pacific Northwest conifers that occur in both urban and rural forests are likely to be sensitive to global change in ways that may limit their distribution in the future. Climate envelope models and tree ring analyses imply suitable habitat is largely defined by climate variables (Littell et al. 2010; Mckenzie et al. 2003; Nitschke and Innes 2008). Additionally, growth and mortality of conifers are known to be sensitive to temperature, soil moisture (likely to decrease with warmer temperatures), and $\mathrm{CO}_{2}$ (Fritts 1974; Gregg et al. 2003; Handa et al. 2006; Holman and Peterson 2006), particularly at seedling stages (Yin et al. 2007). Recent studies demonstrate that tree mortality is increasing in western North America (van Mantgem et al. 2009), raising the possibility of a sudden loss of adult trees. If seedlings are intolerant of future conditions, this creates the potential for rapid and complete forest turnover in the Pacific Northwest. However, urban forests remain understudied, and there is much we do not understand about their ecology. This study seeks to expand our understanding of urban forests and the potential impacts of global change on rural forests by determining the effects of urban influences on the recruitment and growth of an important native conifer, Thuja plicata.

To examine the possibility that conifer recruitment and growth may be susceptible to future global change factors, we quantified the impacts of the urban environment on temperature and nitrogen, two abiotic factors likely to influence trees (and change in the future), and determined how growth and seedling recruitment of $T$. plicata differs between urban forests and rural forests. Motivated by anecdotes and reports of low tree recruitment in state and city parks (Seattle Urban Nature 2009), we additionally compared seedling densities from urban and rural forests to those in nearby old-growth forests. In sum, we used these results to speculate how native conifers in this region will respond to global change. We hypothesized that 1) temperature and soil nitrate are greatest at the edges of urban forests, 2) conifer seedlings are reduced at urban forest edges compared to urban forest centers and rural forests, due to low soil moisture and water stress caused by higher urban temperatures, 3) mature conifer growth is greater at urban park edges than at park centers and rural parks due to the positive effects of an increased growing season length and increased soil nitrate, and 4) conifer seedlings are reduced at all sites relative to old-growth forests.

\section{Methods}

\section{Study sites}

Forest fragments were selected in and around the city of Seattle, Washington to represent both urban and rural locations, and to compare urban influences across a large spatial scale. Criteria for selection of a forest fragment included continuous forest that contained latesuccessional conifers, edges bordered by urban areas as opposed to water, and forest minimally broken up by lawns or open areas. The sites selected were Schmitz Preserve, Westcrest, Interlaken, Northacres, and Carkeek Parks in urban areas, and portions of forest in Cedar River Watershed, Bridle Trails State Park, and Three Forks Natural Area in rural areas (Fig. 1). These park sites are primarily disturbed, second-growth lowland moist forest, with mixed conifer and deciduous trees, as is typical of forested sites in the Puget Trough region, 
and range from approximately 50 to $450 \mathrm{~m}$ in elevation. No study site represents pristine oldgrowth forest, but Schmitz Preserve received only minimal historic logging (Seattle Parks and Recreation 2007). The dominant tree species of the study sites include Douglas-fir (Pseudotsuga menziesii), western hemlock (Tsuga heterophylla), bigleaf maple (Acer macrophyllum), and western red-cedar (Thuja plicata). The scope of our study was limited to a single conifer species, Thuja plicata (Donn ex. D. Don), because it is a late-successional species expected to germinate under closed canopy in the study system and is present at all study sites.

The urban and rural landscapes surrounding our study sites differ in a number of factors, including population density and local air temperature (Table 1). The landscapes around study sites ranged in population density from 5,342 to 11,777 people per square mile for urban sites, and

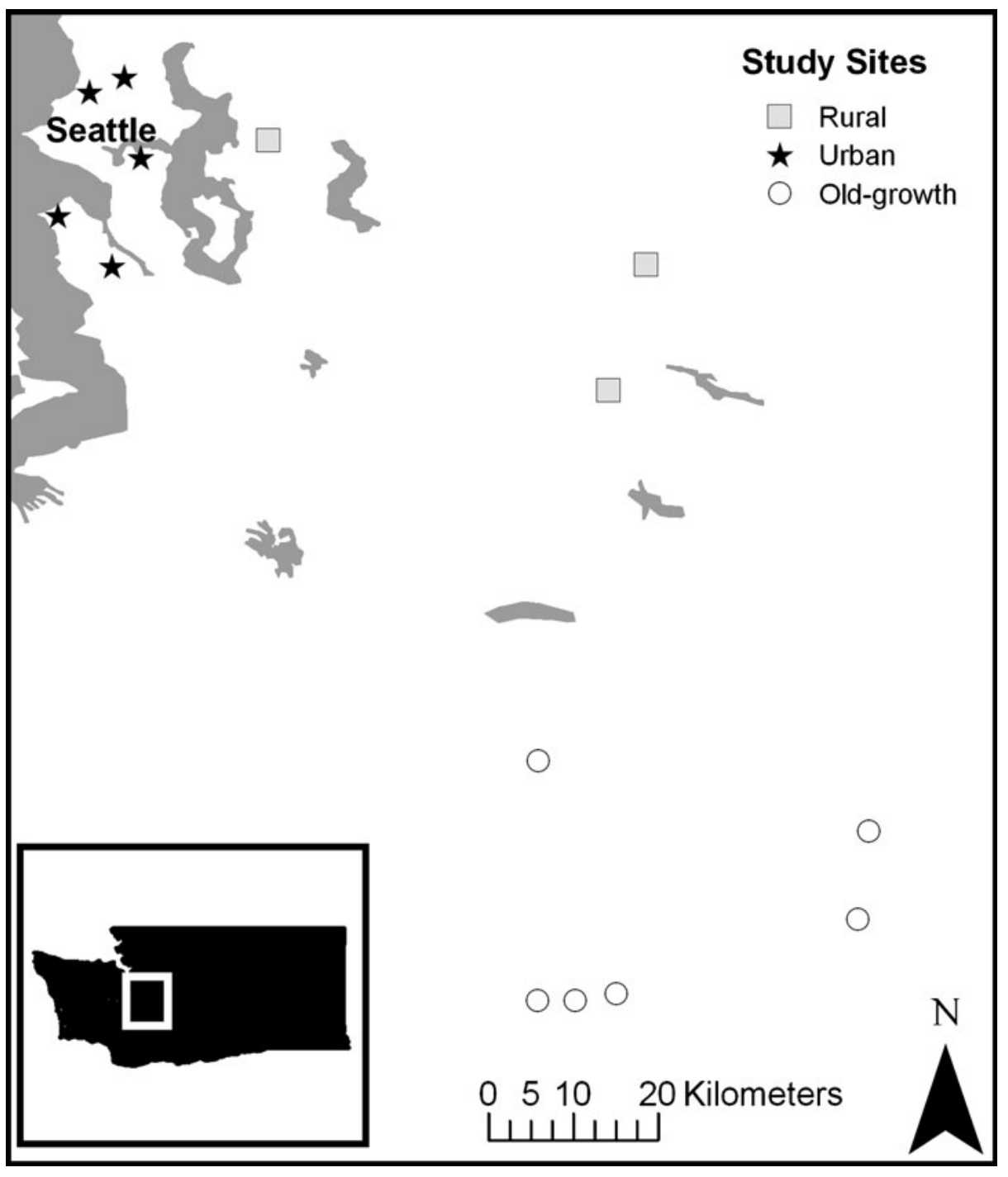

Fig. 1 Park study locations sampled. Urban locations are shown by black stars and are all within the city limits of Seattle. Rural locations are shown by grey boxes, and old-growth sites are shown by unfilled circles and are within Mount Rainier National Park. The inset shows the region of Washington State in which study sites are located 
from 178 to 3,801 people per square mile for rural sites (Washington State Legislature 2011; U.S. Census Bureau 2012a, b). Additionally, mean ambient air temperatures for the duration of temperature data collection were $17.9^{\circ} \mathrm{C}$ in urban landscapes and $14.7{ }^{\circ} \mathrm{C}$ in the landscape around Cedar River Watershed (Menne et al. 2012; Climate Data Online Version 2.0 2012). This difference in mean temperatures is presumably linked to the higher elevation and less urbanized landscape around Cedar River Watershed and should not influence our interpretation of edge vs. center patterns.

To place seedling recruitment in the context of the expected levels for T. plicata, under conditions as free from anthropogenic impacts as possible, we took advantage of an ongoing seedling monitoring study (HilleRisLambers unpublished) in six middle elevation ( $550 \mathrm{~m}$ to $1,050 \mathrm{~m}$ ) old-growth forest stands in Mount Rainier National Park. These forests contain $T$. plicata and other tree species present in urban and rural study sites. Mount Rainier National Park is located on the west side of the Cascade Range, about 90 miles from Seattle. The oldgrowth landscapes are uninhabited, and the forest stands had average air temperatures from 12.6 to $14.2{ }^{\circ} \mathrm{C}$ for the range of dates included in our temperature study (HilleRisLambers unpublished, Table 1). While temperature in these stands nearly overlaps with average temperatures in

Table 1 Characterization of population density, temperature, elevation and slope at study sites

\begin{tabular}{lcccc}
\hline Sites & Population density $^{\mathrm{a}}$ & Temperature $\left.^{\circ}{ }^{\circ} \mathrm{C}\right)^{\mathrm{b}}$ & ${\text { Elevation }(\mathrm{m})^{\mathrm{c}}}^{\mathrm{c}}$ & Slope $\left.^{(\text {degrees }}\right)^{\mathrm{d}}$ \\
\hline Urban (Seattle Parks) & & $18.6,17.9^{\dagger}$ & & \\
Carkeek & $8,380.22$ & - & 61 & 15.17 \\
Northacres & $5,342.11$ & - & 126 & 2.60 \\
Interlaken & $11,777.34$ & - & 61 & 13.33 \\
Schmitz Preserve & $5,484.56$ & - & 70 & 5.60 \\
Westcrest & $5,484.56$ & - & 123 & 4.52 \\
Rural Parks & & & & \\
Bridle Trails State Park & $3,801.44$ & - & 134 & 4.25 \\
Three Forks Natural Area & 178.21 & - & 129 & 1.13 \\
Cedar River Watershed & 178.21 & $14.7^{\dagger}$ & 470 & 8.82 \\
Old-growth & & & & \\
TO04 & 0 & 13.7 & 642 & 4.70 \\
TB13 & 0 & 14.2 & 792 & 8.38 \\
AG05 & 0 & 13.7 & 913 & 12.30 \\
TO11 & 0 & 13.7 & 564 & 2.48 \\
AO03 & 0 & $12.6^{\ddagger}$ & 854 & 11.18 \\
AB08 & 0 & $12.8^{\ddagger}$ & 1,041 & 4.84 \\
\hline
\end{tabular}

\footnotetext{
${ }^{\text {a }}$ People per square mile at the scale of the state legislative district. For Schmitz Preserve and Westcrest Parks, the district data are modified to exclude a large, rural, offshore island outside of Seattle (Legislature 2011; U.S. Census Bureau 2012a, b). Population density varies within larger, rural districts, and actual density of rural landscapes is likely between 178 and 3,801. Old-growth sites have no human population

$\mathrm{b}$ Temperature data are presented as an average for the dates included in the current study (August-early October), and are either collected with temperature sensors (HilleRisLambers unpublished), or collected by climate stations and accessed online (Menne et al 2012; Climate Data Online Version 2.0 2012). Climate station data is denoted by ${ }^{\dagger}$. Data including some extrapolated missing values are denoted by ${ }^{*}$

${ }^{\mathrm{c}}$ Elevations are reported as the midpoint between minimum and maximum elevation for study sites

${ }^{\mathrm{d}}$ Slope is calculated as the mean of slopes within a $10 \mathrm{~m}$ radius of each focal tree for each urban and rural park, and the mean slope across the whole site for old-growth forests
} 
rural sites, variation in temperature in these old-growth sites is most likely driven by elevation rather than by proximity to a forest edge or human population.

\section{Experimental design}

At each urban and rural study site we selected six locations, which we classified as either "center" (located roughly in the center of a forest patch and surrounded by forest) or "edge" (located on the edge of a forest), so that locations were either urban or rural (forest type) and were either on the edge or in the center of a forest fragment (location type). Locations therefore lie on a gradient of increasing urban influence from rural forests, to urban forests, to urban forest edges, and also capture edge effects in both urban and rural forests. At each location, a mature $T$. plicata tree was selected for data collection. In some cases, park features, such as playgrounds or maintained fields, made tree selection or data collection impossible, and as a result two selected locations could not be included in the study. In total, 46 locations were included: 19 urban forest edge locations (4 locations without a T. plicata tree), 9 urban forest center locations (2 locations without a T. plicata tree), and 9 each of rural forest edge and forest center locations.

To characterize how environment varies from edges to centers of both urban and rural forests, air temperature and soil nitrogen were quantified. Air temperature was measured at all locations by hanging sensors (iButtons, made by Maxim Integrated Products) 1-2 $\mathrm{m}$ off the ground. These sensors collected hourly temperature data from August to early-October. For a portion of the study locations, soil samples collected from $0 \mathrm{~m}$ and $10 \mathrm{~m}$ on the transect were mixed, then analyzed using potassium chloride $(\mathrm{KCl})$ extraction methods for nitrate $\left(\mathrm{NO}_{3}{ }^{-}\right)$content. The 33 locations analyzed included 20 urban forest sites (11 edge and 9 center) and 13 rural forest sites (7 edge and 6 center). While both $\mathrm{NO}_{3}{ }^{-}$and ammonium $\left(\mathrm{NH}_{4}{ }^{+}\right)$are available to plants in soil, only nitrate levels were measured because soil nitrate appears to be more important than ammonium to conifer species in our region (Krajina et al. 1973), and because similar effects or patterns between nitrate levels and ammonium levels would be expected (Lovett et al. 2000).

In urban and rural forest fragments, seedling recruitment was surveyed around each focal $T$. plicata tree by counting seedlings, which were defined as first-year germinants and individuals less than 6 in. in height, in $1 \mathrm{~m}$ square plots centered at $2 \mathrm{~m}, 4 \mathrm{~m}, 6 \mathrm{~m}, 8 \mathrm{~m}$, and $10 \mathrm{~m}$ along a randomly determined transect from the central conifer tree. One urban forest edge location with a T. plicata could not be surveyed for recruitment due to park features. Seedling surveys in oldgrowth forests at Mount Rainier were conducted in the same years and using the same methods as the present study, with densities surveyed in six $1 \mathrm{~m}$ square plots per location (six). The surveys were conducted in the centers of selected one-hectare permanent study sites established in the 1970s as part of a Permanent Sample Plot Network (Dyrness and Acker 2000).

To observe growth, increment borers were used to take a thin horizontal cross-section core of wood from focal $T$. plicata trees in urban and rural forests at breast height. Tree diameter at breast height $(\mathrm{DBH})$, the same level as the core, was recorded and used to estimate current basal area. We also estimated basal area 10 years ago, using ring widths measured from the increment core. Relative growth rate was calculated as the amount of estimated basal area grown in 10 years relative to estimated basal area 10 years ago. Out of 40 trees sampled, one tree from an urban forest center location was rotten, and the core could not be analyzed.

Data analysis

Generalized linear mixed effects models were used to determine how forest type (urban, rural) and location type within the park (edge, center) were related to the abiotic (temperature, nitrate) and biotic (seedling density, growth) response variables of interest. 
Distributions were specified as Normal for temperature, log Normal for nitrate and relative growth rates, and Poisson for seedling density. For these analyses, forest type, location type, and their interaction were categorical explanatory variables for our continuous response variables. We also used generalized linear mixed effects models to test whether seedling densities overall, regardless of plot location, differed between urban, rural and old-growth forests. We specified a Poisson distribution for seedling densities in this analysis as well.

For each response variable, we included study site identity as a random effect. Site identity random effects can help account for the differences in unmeasured variables between plots (within and between parks) that we expect may also influence the response variables, such as soil type or forest age. We determined the appropriate structure for this random effect (random slopes or random intercepts) in these models by fitting the most complicated model (i.e. with all explanatory variables and their interactions) with or without study site identity as a random effect. The best fit model from those two models was selected and the random effects of that model were used to fit all fixed effects models (Zuur et al. 2009). Next, the fixed effects models were fit including none, all, or some of forest type and location type explanatory variables (Table 2). For all models of air temperature, time of day was included as an explanatory variable to account for diurnal cycles, and models with interactions between time of day and other fixed effects in analyses were also fit. Finally, the model that best explained the observed variation in the response variables of interest was selected using AIC statistics.

We excluded seedling density data from one park, because surveys were conducted much later in the growing season than at other parks, and this may have affected the density of germinants. This exclusion did not qualitatively influence the results. To compare observed seedling density at urban and rural forests to seedling density levels in old-growth conditions, we tested a second linear mixed effects model of seedling density. The random effects and fixed effects structure was determined as above with Poisson error, but the fixed effect of site type between urban, rural, and old-growth forests was only compared to the null model.

Additionally, as the data were analyzed, it became clear that the selected study trees from urban areas had smaller diameter than the selected study trees from rural areas $(P<.001$ in a Welch's $t$-test of DBH). Since relative growth rates are known to vary with tree size (Fritts 1974), we therefore tested if trees in different forest and location types grew at different rates

Table 2 Differences in AIC values for models explaining observed variation in soil nitrate levels, temperature, T. plicata growth and seedling recruitment. Best fitting models are indicated by AIC values that are in bold

\begin{tabular}{lcccc}
\hline Model $^{\mathrm{a}}$ & Soil nitrate & Temperature & $\begin{array}{l}\text { Growth } \\
\text { (relative growth) }\end{array}$ & $\begin{array}{l}\text { Recruitment } \\
\text { (seedling density) }\end{array}$ \\
\hline Null & 105.8 & 28621.8 & 99.2 & $\mathbf{9 3 . 1}$ \\
Forest (urban or rural) & $\mathbf{1 0 2 . 4}$ & 28620.4 & $\mathbf{9 3 . 7}$ & 94.3 \\
Location (edge or center) & 107.3 & 28561.3 & 101.2 & 93.0 \\
Forest + Location & 103.8 & 28560.6 & 95.6 & 94.4 \\
Forest*Location & 105.5 & $\mathbf{2 8 5 4 1 . 2}$ & 96.1 & NA $^{\mathrm{c}}$ \\
\hline
\end{tabular}

\footnotetext{
a All models included a 'park' random effect

b All temperature models included a 'day/night' categorical explanatory variable as a covariate. The best fitting model (Forest*Location) included a 3-way interaction between forest type, location type and day/night explanatory variables

${ }^{\mathrm{c}}$ Low overall germination led to too few observations to calculate model parameters
} 
after accounting for size. We fit the same model of relative growth rate as described above, except that DBH was included as a fixed effect in a linear mixed effects model of relative growth rate. Since the best fit random effect structure did not change with the inclusion of DBH as a fixed effect, this model is directly comparable to the model of growth rate described above.

Model selection, for all models and for both random and fixed effects, was based on Akaike's Information Criterion (AIC), and the most parsimonious model within two AIC units of the lowest AIC value model was selected as the best model (Burnham and Anderson 2002). Generalized linear mixed effects models were fit using maximum likelihood (ML), with restricted maximum likelihood (REML) used first to determine the appropriate random effects structure, and the Laplace approximation was used for all models of seedling recruitment. All modeling was done using R version 2.12.2 (R Development Core Team 2011) with package lme4 (Bates et al. 2011).

\section{Results}

We found that urban and rural forests differed in environmental characteristics. Specifically, we found that temperatures were higher in urban forests as compared to rural forests, higher at forest edges as compared to forest centers, and that the temperature difference between forest edges and centers was greater in urban forests (Table 2). Moreover, the temperature differences between forest types and between location types were greater during the day than night (Fig. 2a, b). Notably, temperatures were also warmer in the surrounding urban landscape than within urban parks (Table 1, Fig. 2a, b). We also found increased nitrate in urban, compared to rural, forests, but unlike temperature, nitrate levels did not differ by location type (Table 2, Fig. 2c).
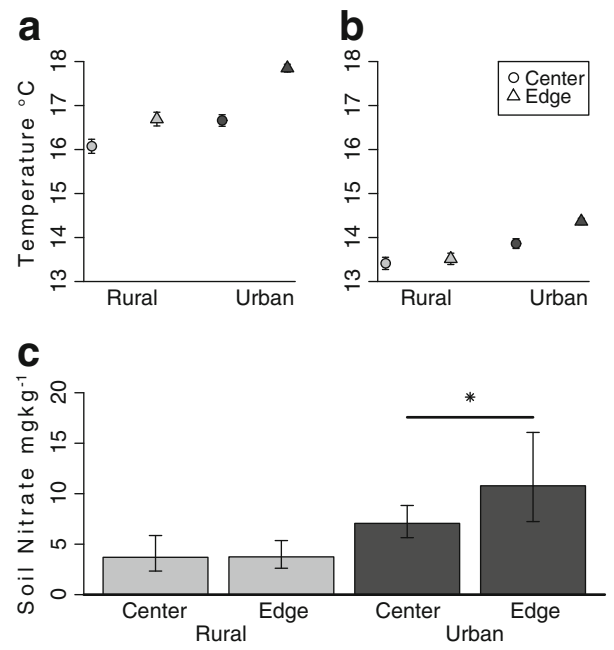

Fig. 2 Average temperatures $\left({ }^{\circ} \mathrm{C}\right)$ are higher in urban versus rural sites, and differ between edges and centers of forest fragments in both rural and urban sites during the day (a) but less so at night (b). Urban areas also have higher nitrate levels ( $\mathrm{mg} \mathrm{kg}^{-1}$ soil) than rural areas (c), but nitrate levels do not differ between park edges or centers. In c) the asterisk indicates areas found to have greater soil nitrate in the best fit models, and error bars represent standard errors of the mean back-transformed from log data (log Normal data). In b) all forest and location type combinations were found to have different temperature in the best fit model 
We found no difference in seedling densities between urban and rural forest types or location types, but tree growth showed a similar pattern to environmental variables. Seedling densities were low across urban and rural study locations, and best fitting models did not include differences based on forest or location types (Table 2, Fig. 3a). Seedling densities were low in urban and rural sites when compared to the old-growth forest sites at Mount Rainier National Park. The model with forest type (here: urban, rural, or old-growth) described the data better than the null model (null AIC: 201.8, model AIC: 195.4), and average germination counts per square meter for T. plicata were much lower at urban and rural sites than at old-growth sites (Fig. 4).

Mature T. plicata growth was greater in urban than rural locations (Table 2), with no correlation to location type in either urban or rural forests (Fig. 3b). When we compared the models of relative growth rate with and without a fixed effect of $\mathrm{DBH}$, the best-fit model contained DBH, urban or rural forest type, location type and the interaction of forest type and $\mathrm{DBH}$. This model included a negative correlation between $\mathrm{DBH}$ and relative growth rate, a positive association between urban areas and faster growth, as well as weak positive association of edges and faster growth. The best fitting model of relative growth rate taking DBH into account has an AIC of 68.8, compared to an AIC of 93.7 for the best fitting model without taking size into account.

\section{Discussion}

Overall, our results suggest that global change will alter the abiotic environment future forests experience, which may have complicated repercussions for tree populations. Specifically, we found clear impacts of urbanization on temperature and soil nitrate (Fig. 2). We expect both temperature and nitrogen to alter tree growth and recruitment (Brown et al. 1996; Fritts 1974; Nitschke and Innes 2008), and consistent with these expectations, we found higher adult tree growth in urban forests (Fig. 3). However, we found low seedling densities relative to old-growth forests (Fig. 4) that did not differ between urban and rural locations, nor edges and centers (Fig. 3). These results imply that effects of future global
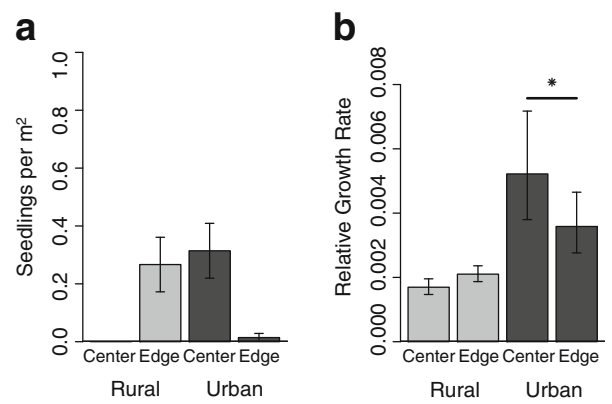

Fig. 3 a) $T$. plicata seedlings per plot $\left(1 \mathrm{~m}^{2}\right)$, averaged by site type. Best fit models do not suggest any differences between forests or locations. b) Relative growth rate for urban and rural trees in forest edges and centers. Relative growth rate was estimated by taking the change in basal area in the tree over the most recent 10 years, divided by the basal area of the tree 10 years before. T. plicata trees in urban areas have faster relative growth rate in best fit models, indicated by the asterisk. Error bars represent standard errors of the mean, and are calculated on variance in: a) Poisson distribution (Poisson Normal data) and b) back-transformed $\log$ data (log Normal data) 


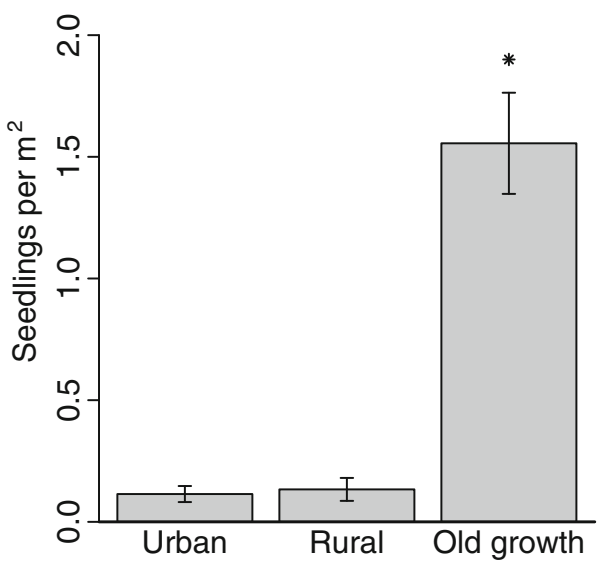

Fig. 4 Overall density of seedlings (per $\mathrm{m}^{2}$ ) is less at urban and rural forests than nearby old-growth forests at Mount Rainier National Park, as indicated by the asterisk. Error bars represent standard errors of the means based on the Poisson distribution

change will likely differ by tree life history stage, and therefore alter population dynamics in ways that are difficult to predict.

Urbanization impacts on the abiotic environment in forest fragments

As in other studies of urban areas, we find that urbanization alters both temperature and soil nitrate (Fig. 2), presumably through urbanization-based increases in albedo (Taha 1997), the use of lawn fertilizers in urban settings, and increased automobile exhaust in cities (Fenn et al. 2003; Pataki et al. 2003). Our results suggest that urban forests can ameliorate the urban influence towards their centers. Urban forest fragment centers stay cool in comparison to urban forest edges, and do not fluctuate as greatly between day and night temperatures, suggesting that forest patches provide some protection against outside anthropogenic impacts. In contrast, while soil nitrate was higher in urban forests, we did not detect a difference in nitrate level between urban forest edges and urban forest centers (Fig. 2). Soil nitrate levels were highest at urban edge sites on average, but they were highly variable among individual locations at urban edges, suggesting that the urban effect on soil nitrate may be more complex than simple edge effects (Weathers et al. 2001), and that nitrate inputs differ on a small scale. This is not a surprising result, since individual owners with property on park edges are likely to use different levels of fertilizer, and otherwise differ in their nitrate inputs to urban forests. Regardless, since urban forest fragments can ameliorate urban temperature influence, they may also be able to mitigate other effects of global change (e.g. pollutants, $\mathrm{CO}_{2}$ ). Consequently, preserving large forest fragments and increasing the density of cover in existing forests could slow some negative effects of global change on urban forests.

Urbanization impacts on T. plicata recruitment and growth

Thuja plicata is known to be extremely sensitive to water stress (Fan et al. 2008), which is why we hypothesized that higher temperatures in urban areas would lead to decreased seedling recruitment and increased seedling mortality, as high temperatures generally 
increase water stress. However, we did not find lower seedling densities in urban forests compared to rural ones. Instead, we found alarmingly low recruitment of T. plicata at all urban and rural study locations compared to old-growth forests (Fig. 4). Other studies have addressed recruitment in regional forests: van Mantgem et al (2009) did not find any decrease in recruitment over the past decades in the west in general, while Broshot (2007) documented reduced regeneration of $T$. plicata and other conifers in an urban core compared to less urban areas in our region. These studies both differ from our study in that they measured recruitment to the sapling life stage rather than to the seedling stage. Furthermore, low recruitment in both urban and rural forests may reflect the younger developmental age of forests in these parks relative to the old-growth forests. Seedling densities for T. plicata are higher near mature, old-growth adult conspecific trees (Keeton and Franklin 2005), of which there were few or none in the urban and rural parks we studied. Alternatively, a non-linear response of decreasing regeneration with increasing temperatures at the landscape level could explain the reduced regeneration in the urban and rural sites compared to old-growth (Table 1, Fig. 2a, b). Finally, it is plausible that despite our attempts to use study locations away from human foot-traffic, urban and rural locations may have received more trampling than the old-growth locations, which would also have contributed to lower observed seedling density in urban and rural sites. The role of water stress in the reduced seedling recruitment we observed remains unclear, and future efforts should assess the effects of air temperature and soil moisture in urban, rural and old-growth forests on water stress and survival in conifer seedlings. As seedlings are rare in disturbed forests, accurate measurement of temperature and soil moisture in the field, followed by growth chamber experiments conducted under those conditions is likely the best option for assessing this relationship.

In contrast to seedling recruitment, adult $T$. plicata tree growth was clearly not limited by urban influences, since trees in urban areas actually grew at faster rates than those in rural areas (Fig. 3). Even when we consider that urban trees may be smaller and that size may affect relative growth rate, the best fit model includes a strong positive association between urban areas and increased growth. Likely, longer growing season (caused by warmer temperatures), higher soil nitrate (Fig. 2), and other factors (e.g. increased light) are favorable to growth of this species in urban forests. We might expect warmer temperatures to lead to water stress in adult trees, as we expected for seedlings. However, it appears that for adult growth, the benefits of increased nitrates, warmer temperatures, or other unmeasured factors overwhelm the potential negative effects of urbanization. Regardless of the cause of the positive association, adult T. plicata individuals experience increased growth in urban areas, which are warmer than other areas. Other studies (van Mantgem et al. 2009) have found increased adult tree mortality with increasing temperatures, which contrasts with our results since increased tree growth is expected to result in decreased mortality (Wyckoff and Clark 2002). These data therefore imply that effects of warming on adult trees may be species or site specific.

\section{Implications for future forests: Conservation and management}

Our results suggest future changes in forest composition through decreases in seedling recruitment in both urban and rural areas. We suspect that factors common to disturbed, but not necessarily urban, forests reduce seedling recruitment. For example, introduced species, which we observed at some urban and rural sites, are known to negatively impact native species through competition (Mack et al. 2000) or herbivory (Nystrand and Granström 2000; Pigot and Leather 2008; Strauss et al. 2009). Regardless of cause, the lack of regeneration is consistent with other observations of early life-history stage 
trees in urban areas (Broshot 2007; Lehvävirta and Rita 2002; Zipperer 2002). With this absence of regeneration, a currently abundant and characteristic species of urban and rural forests, T. plicata, may become rare in future forests.

Thuja plicata has important cultural, economic, and ecological significance in the Pacific Northwest. Adult trees provide shade and aesthetic benefits to people in recreational forests and parks, and are an integral part of regional Native American cultures (Stewart 1984). T. plicata wood is rot resistant, which makes it useful for outdoor structures such as shingle siding on houses (Minore 1983; Winandy and McDonald 1993). In addition to being a common component of mixed-conifer and conifer forests in the region (Burns and Honkala 1990), it is important browse for deer (Coates et al. 1985). Potential future declines of this species, as suggested by the alarmingly low abundance of seedlings we observed in disturbed urban and rural parks, could therefore be devastating, and management efforts should focus on averting its loss. Since we observed high adult tree growth in urban areas, efforts to promote the density and survival of $T$. plicata seedlings should be sufficient for its persistence. However, our study also demonstrates that anthropogenic impacts on urban forests can be multi-faceted and complex. We therefore suggest that additional monitoring and research will be necessary to fully determine which strategies will allow for the maintenance of this characteristic Pacific Northwestern species in both urban and rural forests.

Acknowledgements We acknowledge Howard Hughes Medical Institute Integrated Research Internship Program at the University of Washington Department of Biology (A. O'Brien) and the Department of Energy (DE-FC02-06ER64159 to J. HilleRisLambers) for support. We further acknowledge the National Science Foundation (DEB-1054012AM002 to J. Hille Ris Lambers) for funding. We also thank Brian Buchwitz for advising to A. O'Brien; Aaron Tilley, Irene Weber and Melissa Winstanley for fieldwork assistance; and HilleRisLambers lab members for manuscript reviews and valuable discussion on study design. Finally, we thank the Cedar River Watershed (specifically Amy LaBarge and Chris Raynham), Seattle Parks (specifically Mark Mead), King County Division of Parks and Recreation (specifically Connie Blumen), Washington State Parks and Recreation Commission (specifically Kris Allen and Mary Wellborn), and Mount Rainier National Park for permission to conduct the study.

Open Access This article is distributed under the terms of the Creative Commons Attribution License which permits any use, distribution, and reproduction in any medium, provided the original author(s) and the source are credited.

\section{References}

Bates D, Maechler M, Bolker B (2011) lme4: linear mixed-effects models using S4 classes. Retrieved from http://lme4.r-forge.r-project.org/

Broshot NE (2007) The influence of urbanization on forest stand dynamics in Northwestern Oregon. Urban Ecosyst 10:295-298. doi:10.1007/s11252-007-0023-x

Brown KR, Thompson WA, Camm EL, Hawkins BJ, Guy RD (1996) Effects of N addition rates on the productivity of Picea sitchensis, Thuja plicata, and Tsuga heterophylla seedlings: II. Photosynthesis, 13C discrimination and N partitioning in foliage. Trees 10:198-205. doi:10.1007/BF02340772

Burnham KP, Anderson DR (2002) Model selection and multimodel inference: a practical informationtheoretic approach, 2nd edn. Springer, New York

Burns RM, Honkala BH (1990) Silvics of North America: Volume 1. Conifers. USDA Forest Service, Washington D.C., USA

Carreiro MM, Tripler CE (2005) Forest remnants along urban-rural gradients: examining their potential for global change research. Ecosystems 8:568-582. doi:10.1007/s10021-003-0172-6

Climate Data Online Version 2.0 (2012) National Climatic Data Center, National Oceanic and Atmospheric Administration. Retrieved April 8, 2012, from http://www.ncdc.noaa.gov/cdo-web/search

Coates KD, Pollack JC, Barker JE (1985) The effect of deer browsing on the early growth of three conifer species in the Queen Charlotte Islands. BC Ministry of Forests Research Report RR85002-PR 
R Development Core Team (2011) R: a language and environment for statistical computing. R Foundation for Statistical Computing, Vienna, Austria. http://www.R-project.org

Dyrness T, Acker S (2000) Permanent plots in the Mount Rainier National Park. Permanent Plots of the Pacific Northwest. Report Number 4. http://www.fsl.orst.edu/lter/pubs/webdocs/permplot.htm. Accessed 27 October 2011

Fan S, Grossnickle SC, Russell JH (2008) Morphological and physiological variation in western redcedar (Thuja plicata) populations under contrasting soil water conditions. Trees 21:671-683. doi:10.1007/ s00468-008-0225-8

Fenn ME, Haeuber R, Tonnesen GS, Baron JS, Grossman-Clarke S, Hope D, Jaffe DA et al (2003) Nitrogen emissions, deposition, and monitoring in the western United States. BioScience 53:391-403. doi:10.1641/0006-3568(2003)053[0391:NEDAMI]2.0.CO;2

Fritts HC (1974) Relationships of ring widths in arid-site conifers to variations in monthly temperature and precipitation. Ecol Monogr 44:411-440

Gregg JW, Jones CG, Dawson TE (2003) Urbanization effects on tree growth in the vicinity of New York City. Nature 424:183-187. doi:10.1038/nature01728

Handa IT, Körner C, Hättenschwiler S (2006) Conifer stem growth at the altitudinal treeline in response to four years of $\mathrm{CO}_{2}$ enrichment. Glob Chang Biol 12:2417-2430. doi:10.1111/j.1365-2486.2006.01258.x

Holman ML, Peterson DL (2006) Spatial and temporal variability in forest growth in the Olympic Mountains. Can J For Res 36:92-104. doi:10.1139/X05-225

Keeton WS, Franklin JF (2005) Do remnant old-growth trees Accelerate rates of succession in mature Douglas-fir forests? Ecol Monogr 75:103-118. doi:10.1890/03-0626

Krajina VJ, Madoc-Jones S, Mellor G (1973) Ammonium and nitrate in the nitrogen economy of some conifers growing in Douglas-fir communities of the Pacific North-West of America. Soil Biol Biochem 5:143-147

Lehvävirta S, Rita H (2002) Natural regeneration of trees in urban woodlands. J Veg Sci 13:57-66. doi:10.1111/j.1654-1103.2002.tb02023.x

Littell JS, Oneil EE, McKenzie D, Hicke JA, Lutz JA, Norheim RA, Elsner MM (2010) Forest ecosystems, disturbance, and climatic change in Washington State, USA. Clim Chang 102:129-158. doi:10.1007/ s10584-010-9858-x

Lonsdale W (1999) Global patterns of plant invasions and the concept of invasibility. Ecology 80:1522-1536. doi:10.1890/0012-9658(1999)080[1522:GPOPIA]2.0.CO;2

Lovett GM, Traynor MM, Pouyat RV, Carreiro MM, Zhu W-X, Baxter JW (2000) Atmospheric deposition to oak forests along an urban-rural gradient. Environ Sci Technol 34:4294-4300. doi:10.1021/es001077q

Mack RN, Simberloff D, Lonsdale WM, Evans H, Clout M, Bazzaz FA (2000) Biotic invasions: causes, epidemiology, global consequences, and control. Ecol Appl 10:689-710. doi:10.1890/1051-0761(2000) 010[0689:BICEGC]2.0.CO;2

Mckenzie D, Peterson DW, Peterson DL, Thornton PE (2003) Climatic and biophysical controls on conifer species distributions in mountain forests of Washington State, USA. J Biogeogr 30:1093-1108

Menne MJ, Durre I, Vose RS, Gleason BE, Houston TG (2012) An overview of the global historical climatology network-daily database. J Atmos Ocean Technol, In press. doi:10.1175/JTECH-D-1100103.1

Minore D (1983) Western redcedar-a literature review. Gen. Tech. Rep. PNW-GTR-150. Portland, OR: USDA Forest Service, Pacific Northwest Research Station

Nitschke C, Innes J (2008) A tree and climate assessment tool for modelling ecosystem response to climate change. Ecol Model 210:263-277. doi:10.1016/j.ecolmodel.2007.07.026

Nystrand O, Granström A (2000) Predation on Pinus sylvestris seeds and juvenile seedlings in Swedish boreal forest in relation to stand disturbance by logging. J Appl Ecol 37:449-463. doi:10.1046/j.13652664.2000.00505.x

Pataki DE, Bowling DR, Ehleringer JR (2003) Seasonal cycle of carbon dioxide and its isotopic composition in an urban atmosphere: anthropogenic and biogenic effects. J Geophys Res 108:4735. doi:10.1029/ 2003JD003865

Pigot AL, Leather RS (2008) Invertebrate predators drive distance-dependent patterns of seedling mortality in a temperate tree Acer pseudoplatanus. Oikos 117:521-530. doi:10.1111/j.2008.0030-1299.16499.x

Seattle Parks and Recreation (2007) Park history - the Sherwood files. City of Seattle. http://www.seattle.gov/ parks/history/sherwood.htm. Accessed 27 October, 2011

Seattle Urban Nature (2009) The State of Seattle's Conifer Forests. Seattle

Stewart H (1984) Cedar: tree of life to the Northwest Coast Indians. Douglas \& McIntyre Ltd, Vancouver

Strauss SY, Stanton ML, Emery NC, Bradley CA, Carleton A, Dittrich-Reed DR, Ervin OA et al (2009) Cryptic seedling herbivory by nocturnal introduced generalists impacts survival, performance of native and exotic plants. Ecology 90:419-429. doi:10.1890/07-1533.1 
Taha H (1997) Urban climates and heat islands: albedo, evapotranspiration, and anthropogenic heat. Energy Build 25:99-103. doi:10.1016/S0378-7788(96)00999-1

U.S. Census Bureau. (2012a) 2010 Census redistricting data (Public Law 94-171) Summary file. Washington State Office of Financial Management, Forecasting Division. Retrieved from http://www.ofm.wa.gov/ pop/census2010/data.asp

U.S. Census Bureau. (2012b) State and County QuickFacts. Retrieved from http://quickfacts.census.gov/qfd/ index.html

van Mantgem PJ, Stephenson NL, Byrne JC, Daniels LD, Franklin JF, Fulé PZ, Harmon ME et al (2009) Widespread increase of tree mortality rates in the western United States. Science 323:521-524. doi:10.1126/science. 1165000

Washington State Legislature (2011) Statewide legislative district map with legislative members. Retrieved from http://www.leg.wa.gov/LIC/Pages/legislative documents.aspx

Weathers KC, Cadenasso ML, Pickett STA (2001) Forest edges as nutrient and pollutant concentrators: potential synergisms between fragmentation, forest canopies, and the atmosphere. Conserv Biol 15:1506-1514. doi:10.1046/j.1523-1739.2001.01090.x

Winandy JE, McDonald KA (1993) Material selection and preservative treatments for outdoor wood structures. Wood Design Focus 4:8-13

Wyckoff PH, Clark JS (2002) The relationship between growth and mortality for seven co-occurring tree species in the southern Appalachian Mountains. J Ecol 90:604-615. doi:10.1046/j.1365-2745.2002.00691.x

Yin HJ, Liu Q, Lai T (2007) Warming effects on growth and physiology in the seedlings of the two conifers Picea asperata and Abies faxoniana under two contrasting light conditions. Ecol Res 23:459-469. doi:10.1007/s11284-007-0404-x

Zipperer WC (2002) Species composition and structure of regenerated and remnant forest patches within an urban landscape. Urban Ecosyst 6:271-290. doi:10.1023/B:UECO.0000004827.12561.d4

Ziska LH, Bunce JA, Goins EW (2004) Characterization of an urban-rural $\mathrm{CO}_{2} /$ temperature gradient and associated changes in initial plant productivity during secondary succession. Oecologia 139:454-458. doi:10.1007/s00442-004-1526-2

Zuur AF, Ieno EN, Walker N, Saveliev AA, Smith GM (2009) Mixed effects models and extensions in ecology with R, 1st edn. Springer, New York 